\title{
Development of Cognitive Skills in Serious Mobile Games
}

\author{
Ki-Min Song ${ }^{1}$, Ho-Kyoung Ryu ${ }^{2}$, Seung-Il Moon ${ }^{3 *}$, Joo-Suk Park ${ }^{4}$ and \\ Young-Min Song ${ }^{5}$ \\ ${ }^{12}$ Hanyang University, Seoul, Korea \\ \{haieung,hryu\}@hanyang.ac.kr \\ ${ }^{3}$ Hanyang University, Seoul, Korea \\ moonsi921@hanyang.ac.kr(Corresponding Author) \\ ${ }^{4}$ Seokyeong University, Seoul, Korea \\ Ju310@hanmail.net \\ ${ }^{5}$ Anyang University, Incheon, Korea \\ songymin@anyang.ac.kr
}

\begin{abstract}
21 st century cognitive and collaborative skills can be developed by providing learners with immersive activities where they have to work with others to solve problems. Serious mobile learning games can support such activities by leveraging the affordances of mobile devices such as location awareness, Internet connectivity and multimedia support. This paper describes a serious mobile learning game, developed for the Android platform, designed to allow learners to play the role of business consultants to an organization facing some serious challenges. The game uses mixed reality resources to lead the players through a realistic scenario, providing them with physical, cognitive and collaborative challenges. Focusing on key 21 st century cognitive and collaborative skills, we present the result of an experiment designed to measure the effectiveness of the game in terms of the impact of working with others in higher level learning. We introduce the concept of coordinated individual flow experience as an analytical approach to evaluating the effects of delayed collaborative learning. Our results raise challenging questions about whether some learning experiences that encourage realistic team working may not be entirely compatible with emphasizing cognitive skills.
\end{abstract}

Keywords: Android platform, Virtual augmented reality, Business simulation game, Delayed collaborative learning, Coordinated flow experience

\section{Introduction}

More specific questions of can arise about what skills people will need in the future in order to be able to effectively operate in and contribute to an unpredictably changing world. Thus the debate around 21st century skills; what they are, what they are for, how we teach and assess them, has become increasingly prominent. There is little question that the nature of education must change to meet the challenges of the 21 st century, now that access to information is much easier than it was in the past, and knowledge production and dissemination is a distributed and interactive activity, mediated by ICTs, entailing a shift from knowledge production to knowledge configuration [1]. Whilst a greater level of inclusion in education, particularly higher education, has been seen in many countries, simply producing more graduates is not itself a solution to the problem of educating for a changing world [2]. Rather, there is a widely perceived need to provide an education that is somewhat more pertinent to the needs of both individuals and society. An important aspect of this concept of pertinence is the articulation between education and work [3] with the world of work itself moving from the large, long lived organizations of the past to small, often self-started, entrepreneurial enterprises [4]. 
Much has been written about what types of skills a 21st century learner needs to develop. In general, the core skills are from the higher levels of Bloom's taxonomy; analysis, synthesis and evaluation in the original taxonomy, analyze, evaluate and create in the revised taxonomy [5]. However there is often a broader conception than these purely cognitive skills in defining a full ideal skill set for the 21 st century learner. For example, aspects like cross cultural adaptability [1], new media literacies [6], interpersonal and intrapersonal skills [7] are also frequently stressed. In addition, as well as skill requirements that are well established but may be changing in terms of their capacity and context, such as collaboration, other skills are newly required, such as the ability to filter out meaning from the mass of information only recently made available to us [8]. This has implications for the nature of remembering in the revised Bloom's taxonomy; remembering factual knowledge is less important in an information rich environment, but other forms (conceptual, procedural and meta-cognitive knowledge) become thus more important.

Given the broad range of possible skills required by the 21 st century learner, it is unlikely that a single serious game is able to address all of these to the same degree. Therefore we can expect that different serious games will address different combinations of skill, with different emphases. In the next section we provide an indicative sample of some serious games, including mobile games, highlighting some of the areas of skill that they seek to develop. We also indicate where our own mobile serious game fits into this domain of interest.

\subsection{Serious Games for Skills Development}

Digital, game-based learning has become an increasing focus for educational researchers [9],[10]. Serious educational games are directed at problem solving in the context of engaging learning experiences [11]. Although serious games may have entertainment value, this is the means rather than the end, intended to increase the motivation to learn. The assumption is that the pairing of instructional content with certain game features will engage users and thus achieve the desired instructional goals [12]. This type of game-based entertainment can also be used to simulate a learning context where real world learning would not be possible due to factors such as cost, risk or scalability. For example games have been used for training in the military [13] and for fire fighters [14], where cost and risk of learning in the real world is extreme. One popular domain for serious games is within a business curriculum [15]. For example [16] describe a longitudinal web based game that simulates a business consulting exercise, while [17] describe an MMS-based game in which students reflect on the new digital economy. Given the scale of international business education, scalability can be an important issue for educators in this domain. The game described in this paper also addresses the business domain, and involves the simulation of business consultancy, which is difficult to achieve in the real world for large numbers of students.

\subsubsection{Mobile Augmented Reality Serious Games}

Serious games are increasingly finding their way onto mobile devices, and there have been many such games that have involved elements of augmented reality. 'Environmental Detectives' [18] put players in the role of environment experts in charge of investigating a toxic leak at a real geographical location. The players carried location-aware devices that allowed them to collect virtual field evidence and interview virtual characters to achieve their goals. In 'Premierloytnant Bielke' players used a mobile game to learn about the local history of their city by reproducing the steps of a soldier trying to build gunboats in the same city in the 1800s. [19] describes using an augmented reality game, 'Reliving the Revolution' to explicitly teach 21 st century skills. The game used a combination of physical and virtual objects in a real location, and allowed participants to 'relive' the 
Battle of Lexington and try to work out who fired the first shot. The game was nonlinear with time constraints and players had distinct roles, with different perspectives. According to the published research, players became more open to diverse opinions and understood the necessity for applying multiple perspectives to current global and community issues. Playing in pairs, the participants needed to collaborate and explore the game together. Our own game follows a similar path to a number of these previous examples in putting players into specific roles while exploring a geo-tagged environment, and exposing them to different perspectives on the same context, while seeking to solve a given complex problem.

\subsubsection{Virtual Augmented Reality Games}

One particular type of mobile learning game involves virtual augmented reality, where the augmentation of the game is not applied to real physical sites (such as buildings or geographical features) but imagined ones. In Savannah [20] participants role-played a pride of lions trying to survive in a virtual African environment. This virtual world was overlaid on available locations such as a school playing field. A similar idea was explored in 'Invisible Buildings', where participants explored an entirely virtual buried Roman Villa [21]. Invisible Buildings also involved the integration of physical artifacts that helped to link the virtual reality with the physical experience of the players. In 'Alien Contact!' [8] players were presented with a scenario where aliens have landed on Earth and seem to be preparing for a number of possible actions. In teams of four, in different roles, players interviewed virtual characters, collected digital items, and solved puzzles to find out why the aliens had landed. At the end, players orally presented their findings to the class. This potential for mixing the real, the augmented and the virtual to provide new types of learning experience, along with the blending of mobile and class based activity, has been one of the motivations behind the game described in this paper. It should be noted that a major advantage of creating such virtual augmented reality games is that they can be configured to be played in any physical location, since they do not rely on specific physical features to support their virtual aspects.

\subsubsection{Mobile Learning on the Android Platform}

There is an increasing amount of published work that describes mobile learning projects specifically for the Android platform, often taking advantage of specific device features. used Android devices to teach English in the context of visiting a zoo. The use of a touch screen was important to the application, as it included activities such as a jigsaw puzzle that relied on this feature. 'Gymkhanas', a multimedia mobile learning game that involved the exploration of a physical environment used the GPS feature, along with web services, photographs and messaging services. Describe the design of a location-based serious mobile game for people with intellectual disabilities and additional sensory impairments that used some tools specifically available for the Android platform such as the 'eyes free' project. Also used Android devices to assist those who have learning challenges, teaching first aid skills to individuals with Autism. Developers of serious mobile learning games have begun to migrate to the Android platform for a number of reasons, including touch screen interaction, multiple modes of wireless communication, multimedia support, location awareness, ease of deployment, affordability and ubiquity. We have taken advantage of many of these features in our own implementation.

\section{Flow Experience}

One of the analytical tools that can be deployed in examining the process of game play is flow experience [22]. [9] surmised that the best learning moments usually occur when a learner is stretched to the limit in accomplishing something challenging and worthwhile. Many other studies have confirmed that game-based learning activities can provide 
enjoyment, and are therefore able to maintain motivation to learn, and Csikszentmihalyi's 'Flow Theory' has provided a framework to depict users' positive or negative experiences in a three-channel model, as shown in Figure 1.

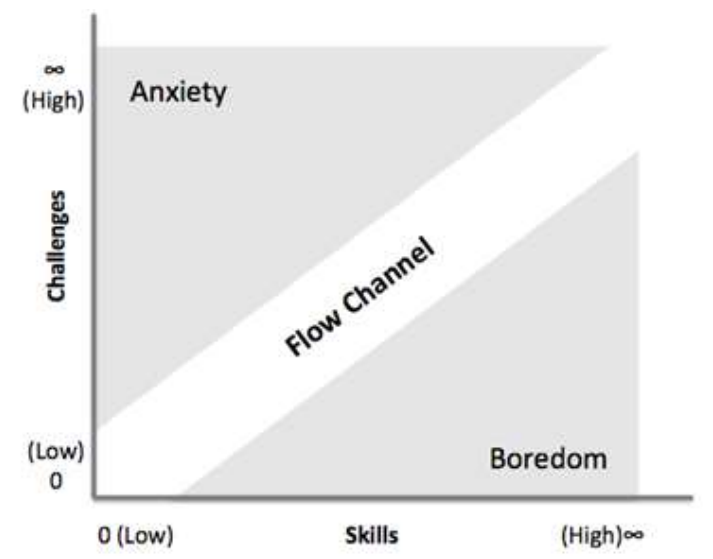

Figure 1. Three Channel Flow Model (from [22])

The three-channel segmentation model of flow is based on matching a person's skills in a given activity with their perceptions of the challenges of the activity. In the model, anxiety will result if the level of challenge is too high for the current level of skill, while boredom will result if the level of challenge is too low. The definition also states that there is a critical minimum level that both skills and challenges must meet for flow to be experienced.

In many studies [23], optimal flow experience is characterized in four dimensions. These incorporate the extent to which (a) the learner perceives a sense of control over the learning activity, (b) the learner perceives that his or her attention is focused on the learning activity, (c) the learner's curiosity is kept aroused during the learning activity, and (d) the learner finds the learning activity intrinsically interesting. Achieving a balance between skill and challenge is a key component of all four dimensions. Later in this paper, we examine some aspects of flow experience in the analysis of our learning game.

\section{Designing the Game}

The game described here primarily uses the location awareness (supported by webbased mapping tools) and multimedia features of Android devices, while from a usability perspective it also takes advantage of touch screen features (for example to zoom the map) and the ability to provide multiple tabbed views, enabling players to easily switch between different tools while playing the game. However, despite the broad range of impressive technical features available on current mobile devices, these alone cannot make a game either engaging or pedagogical. Thus we need to find ways to embed both effective gaming experiences and worthwhile learning outcomes into the same application.

Our game is in essence an augmented, virtual reality outdoor mobile learning game designed for two players. It follows a narrative learning path, reflected by a physical path through a series of geo-located waypoints, as players move around a physical location that represents a virtual set of destinations. Important to the concept of the game is that the physical locations represent virtual aspects of a fictional organization. For example, when configuring the game, various real world buildings can be chosen to represent the various departments in the organization. In our experiments, different buildings on campus have been used to play the roles of these departments. Players, in the role of business consultants, navigate to locations and investigate a problem presented to them at the beginning of the game, which is the context of a fictional mobile phone manufacturing 
company that is having some problems. Each physical location represents a part of the company, and reveals both virtual and physical artifacts (videos, questions, documents) and each of these resources unfolds a series of perspectives on the problems faced by the company. As they engage in the game, players have to gather, analyze and reflect on various (and sometimes conflicting) pieces of information. The game aims to teach $21^{\text {st }}$ century cognitive skills, in particular analysis (what does this tell me?), synthesis (how do these different sources relate to one another?) and critical thinking (why am I getting different stories from different people?) Of equal important to the cognitive skills are the collaborative aspects. The game is non-zero-sum; one player does not win at the expense of the other, rather both players 'win' together, because the decisions made jointly by the players determine the outcome of the game.

\subsection{The Game Narrative}

It is important that games have some kind of narrative flow that leads the player through the game in a way that unfolds over time. The core narrative that we have adopted in our game is taken from Larsen's model of standard linear fiction as described in [24]. This model draws the player through a series of game stages: teaser, elaboration, conflict escalation, climax and resolution. Adopting Larsen's model, the current narrative of the game contains the minimum number of activities to implement the framework. The concept of conflict escalation in the context of a two player game is introduced by having branching game paths.

The diagrammatic representation of a sequential-move game is commonly referred to as a game tree [25]. Figure 2 shows a game tree representing the stages in our business consulting game. Each node in the tree relates to a physical location, a virtual location, an interview with a character in the game, an artifact and a set of questions. In the figure we show the various characters' names and virtual locations, mapped to the elements of the narrative flow described above. The teaser lays out the initial problem to the players and leads them to the elaboration. After this stage the two players are sent to different 'departments' in the company and are given conflicting information. The climax gives them the final piece of the jigsaw that should help them to the point of resolution. At the resolution stage the players provide feedback about the issues they have identified as causing the problem under investigation. All player responses are scored for correctness, the final score is announced to the players, and the mobile game ends, though the activity continues with a classroom-based feedback session.

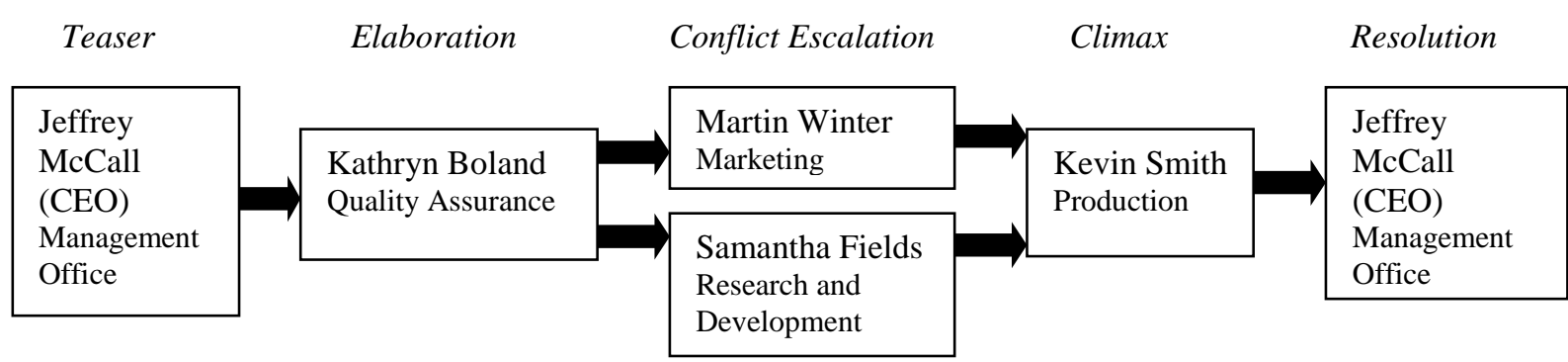

Figure 2. Game Tree for the Business Game

\subsection{Game Evolution}

The game that we describe here is the latest generation of a mobile learning game that has been in development over the last two years or so. The initial version was written using Java Micro Edition and designed to run on the Symbian S60 platform. While technically usable the game proved limited in both player engagement and learning outcomes. As a result of evaluating this first version, we made considerable improvements to the engagement and pedagogy of the game, basing the game play around 
a more engaging narrative, integrating physical artifacts into the information gathering process, and providing more learning points in the game. Despite these improvements it became clear that the programming language and platform that were being used did not provide a viable future development path. Therefore a decision was taken to completely redesign the game for the Android platform, to ensure that future versions of the game would be accessible to a wide range of educators. This is the version that is evaluated in this paper.

\section{Description of Gameplay}

Prior to the game, players need to be briefed on the objectives of the game, and how it works. The normal expectation is that players operate in groups of two. This enables team play, and is also important as part of the conflict escalation element of the game, which assumes that the two players will be given different information from different virtual characters, and be required to discuss and resolve these conflicts. However for experimental purposes we also enabled a single player mode.

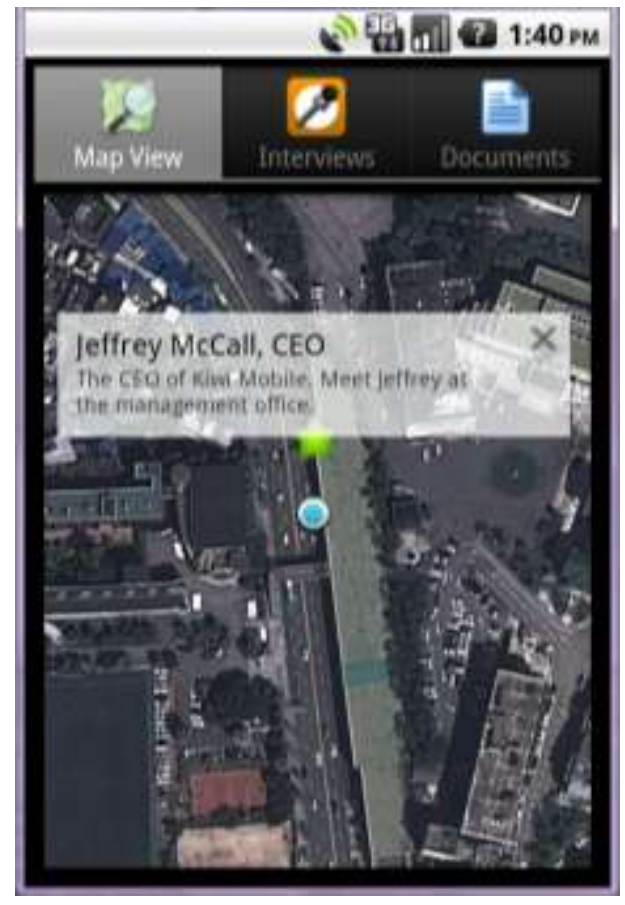

\section{Figure 3. Map View with Position and Captioned Waypoint}

The game begins in a similar manner to many other location aware learning activities. The current position of the player is shown on the map (as a blue disc), while the first waypoint is also indicated (as a green star). As one aspect of the augmented virtual reality features of the game, the next waypoint is also captioned with the name and location of the next interviewee. For example in Figure 3, the initial map view of the game is shown, with the first waypoint captioned as the CEO at the management office.

When a player reaches a waypoint, a video 'interview' is automatically triggered. Each interview is given by a different character from a different department of the fictional company. In the interview, as well as information being provided about that person's perceptions of the company's difficulties, each character also refers to an artifact that the player must locate and look at. These artifacts are physical, rather than virtual, and are positioned at the waypoints. Once the player has watched the interview video and looked at the artifact, they are given the opportunity to ask the interviewee only one of three 
possible follow-up questions. These questions are designed in such a way that the players must decide which question is the 'best' one to ask, to identify the question that is most likely to provide the most valuable additional information. For example at the first interview point, players are presented with the three qualitatively graded question options shown in in Figure 4. These follow on from a video interview in which the CEO has described a negative news story about a battery in one of the company's phones that apparently caught fire. The CEO expresses the opinion that the story is false, and that the main problem facing the company is a failure of public relations and marketing. This is associated with an artifact (the complete newspaper article). For the players, the first question in the list is designed to be the least useful question in the context of the previous interview, where the interviewee makes it clear in the video that they believe the news story to be groundless. Asking this question is unlikely to reveal new information, so it scores the lowest (though it does score more than not asking any questions.) The second option is more likely to reveal useful information, as it may uncover other issues that have been in the public domain, so scores more than the first question. However the third question is designed to be the most appropriate to ask, as it may reveal insights into issues within the company that are separate from the news story and may not be in the public domain, and therefore scores the highest. Players are unable to view the answer to more than one question per interview.

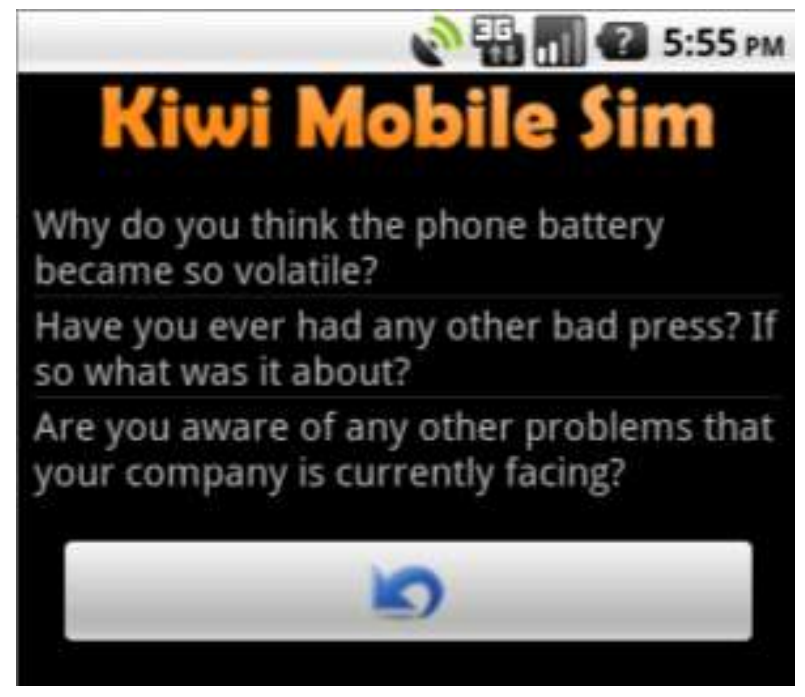

\section{Figure 4. Qualitatively Graded Question Options}

In terms of team play, the most important point in the game is the 'conflict escalation', where each player in the pair is directed to a different waypoint. Player 1 is directed to the marketing department, while player 2 is directed to research and development. The idea at this point is that each of the virtual interviewees blames the other for some of the problems that the company is facing. Then the two players will meet again at the following waypoint, and need to discuss the conflicting information that they have been given.

The penultimate waypoint in the game provides a kind of resolution, in that it answers the original question posed by the teaser, namely, why did the phone battery catch fire? The final virtual character explains that there is a problem with the layout of the assembly hall that has led to batteries being damaged while in storage, and that this has led to the battery fire. Whilst this answers the question initially posed in the game, it is important that in the process of getting to this point the players have also been given a range of other information about the company that points to other serious problems that need to be resolved. At the final waypoint, the players are taken back to their original point of 
departure, the CEO's office, and asked what they have found out. They are then presented with a multiple choice set of questions asking them which are the main problems the company is facing. Finally they are asked to enter a free text opinion on the issues they think are most important. The learning activity does not finish with the conclusion of the game. Rather, it leads in to the second part of the blended learning process, where the teams are given the opportunity to present their findings back to the rest of the class in a similar manner to 'Alien Contact!' [8].

\section{Evaluation}

We have used a number of types of evaluation at various stages in the game's evolution, looking at various aspects of the learning process. These have included questionnaires, interviews, participant observations, log file analyses and classroom discussions. In this paper, with a focus on 21 st century cognitive and collaborative skills, we describe an experiment that looks primarily at some core cognitive skills and a comparison of single player experience versus teamwork, assessed through log file data and questionnaires given to game participants.

\subsection{Methods}

We undertook an evaluation in which a small number of learners experienced one of two different versions of our serious mobile learning game; one version used a single player mode, the other a pair-playing mode. The main purpose of this particular evaluation was thus to explore what aspects of learning experience could be associated with co-operative learning activities, and what different learning outcomes might result from such collaboration. The two types of learning configurations (single player, and collaborative learning) were deployed to assess the differences in both learning outcomes and flow experiences rated by the participants. The nature of the collaborative learning emulated a common work practice in any business sector where workers might collect information or propose solutions individually, only later being able to discuss their data and conclusions with others. We term this delayed collaborative learning. One proposal is that this work practice might lead them to feel bored or frustrated, an observation that we will return to in this empirical study.

As described earlier in this paper, in single playing mode, all five waypoints in the game will be visited, while in pair-playing mode, each subject only personally visits four waypoints. This experimental setting thus required each pair to visit and interview the five departments collaboratively and subsequently coordinate what they learnt at each location. For the evaluation, a total of 21 subjects, all first-year students at Hanyang University, Seoul, Korea, voluntarily participated; seven single players and seven pairs carried out the experiment. Each game session lasted around half an hour, and each participant received a $\$ 10$ reward for their time contribution.

\subsection{Results of Log File Analysis}

The results presented here are taken from two sources, player scores as recorded in the $\log$ files of the mobile devices used for the game, and responses to questionnaires administered to the participants. We begin with the results of the log file data (Table 1). This can be said to reflect some aspects of the application of cognitive skills since, as we have seen, points are scored by critically thinking about questions posed within the game. As a crude measure, a higher score is interpreted to indicate that critical thinking skills have been more effectively applied. A somewhat surprising result for us was that the single players generally outperformed the team players on this measure. Notwithstanding the fact that the scoring mechanism is open to interpretation, and may not be regarded as an objective measure of higher level skills being applied, it is nonetheless striking how consistently the single players scored higher than the team players. It should be note that 
team players, despite working together, will typically end up with different totals because they answer some questions individually during the 'conflict escalation' phase of the game, and may also disagree with each other and select different questions. We will return to these results later, but first we will present the results from the questionnaires.

Table 1. Game Scores from Log File Data

\begin{tabular}{|c|c|c|c|}
\hline $\begin{array}{c}\text { Test } \\
\text { Results }\end{array}$ & \multicolumn{2}{|c|}{$※ \alpha=$ max score } \\
\hline & \multicolumn{2}{|c|}{ Team player( $\alpha=117)$} & single $(\alpha=140)$ \\
\hline & player1 & player2 & player3 \\
\hline 1 & 81 & 84 & 107 \\
\hline 2 & 71 & 84 & 92 \\
\hline 3 & 79 & 74 & 92 \\
\hline 4 & 83 & 67 & 114 \\
\hline 5 & 66 & 71 & 109 \\
\hline 6 & 81 & 84 & 102 \\
\hline 7 & 101 & 81 & 99 \\
\hline avg & 80.28571429 & 77.85714286 & 102.1428571 \\
\hline avg/ $\alpha$ & 0.686202686 & 0.665445665 & 0.729591837 \\
\hline
\end{tabular}

\subsection{Results of Questionnaires}

The results described in this section were gathered from questionnaires administered to the participants after they had played the game, either individually or in pairs. These questionnaires contained a series of statements to which the participants were asked to respond on a 7 point Likert scale where 1 was 'strongly disagree' and 7 was 'strongly agree', with 4 the neutral value. Most parts of the questionnaire were common to all participants, but three statements were only addressed to the paired players, relating to their experience of playing with delayed collaboration.

The first two statements were about how our participants perceived the value of using mobile game-based learning as a way of learning about the given business problem. The responses to statement 1 revealed that the respondents who played alone (i.e., single players) saw a unique value in delivering these learning goals using a mobile solution, and a clear advantage over using a more traditional PC based e-learning solution. However, the team players did not see a great advantage in using the mobile solution (Table 2). This may be because in the delayed collaboration mode, players were forced to by physically separated from their partners for part of the game. This may have been perceived as a negative feature that would not have impacted on single players. We might therefore speculate that delayed interaction through physical separation, though realistic, may have a negative impact on collaborative learning. Both one-sampled T-tests against the neutral value (4.00) and independent samples T-test confirmed this interpretation.

Table 2. Value of Mobility

\begin{tabular}{|c|c|c|c|}
\hline \multirow{2}{*}{ Statement } & \multicolumn{3}{|c|}{ Mean ratings (s.d) } \\
\cline { 2 - 4 } & Single $(\mathrm{n}=7)$ & Pair $(\mathrm{n}=14)$ & $\mathrm{p}$ \\
\hline $\begin{array}{c}\text { 1. My learning about the business ideas } \\
\text { covered by the game would be difficult to } \\
\text { achieve using other methods. }\end{array}$ & $5.43(0.98)^{*}$ & $4.57(1.40)$ & $<.05$ \\
\hline 2. The game would be better played on a PC. & $4.14(1.35)$ & $4.00(1.66)$ & n.s \\
\hline
\end{tabular}

* One-sampled T-test, significant at level $\mathrm{p}<.05$ 
An important aspect of addressing $21^{\text {st }}$ skills in a collaborative context is to examine how cognitive skills are being developed and applied. The most important questions are about whether the game-based learning activity had encouraged the application of higherlevel skills; analysis, synthesis and critical thinking to establish possible solutions either individually or cooperatively. Responses to statements 3, 4, and 5, which address some of these skills, are summarized in Table 3.

Table 3. Cognitive Skills

\begin{tabular}{|c|c|c|c|}
\hline \multirow{2}{*}{ Statement } & \multicolumn{2}{|c|}{ Mean ratings (s.d) } \\
\cline { 2 - 4 } & Single (n=7) & Pair (n=14) & $\mathrm{p}$ \\
\hline $\begin{array}{c}\text { 3. I felt able to identify some major } \\
\text { business issues being presented in the } \\
\text { game. }\end{array}$ & $6.00(0.58)^{*}$ & $5.21(0.70)^{*}$ & $<.05$ \\
\hline $\begin{array}{c}\text { 4. I was able to identify solutions to the } \\
\text { problems faced by the fictional company } \\
\text { presented by the game. }\end{array}$ & $5.71(0.49)^{*}$ & $4.79(1.12)$ & n.s \\
\hline $\begin{array}{c}\text { 5. I was able to gather items of } \\
\text { information from different stages of the } \\
\text { game and identify relationships between } \\
\text { them }\end{array}$ & $6.29(0.95)^{*}$ & $5.36(0.93)^{*}$ & n.s. \\
\hline
\end{tabular}

* One-sampled T-test, significant at level $\mathrm{p}<.05$

Looking at statement 3 , the single players felt they could identify the business issues more easily than the team players. Perhaps this may arise from the lack of direct information from the sites not visited by each of the individuals in the pairs. However, there are no significant differences in the responses to statements 4 and 5 , relating to solutions and information (the independent samples T-test confirmed this interpretation). This is interesting, since the game was deliberately designed to provide conflicting information to require the learner to apply higher levels skills of critical thinking. Responses to these two statements (4 and 5) suggested that the equivocal nature of the information supplied was recognized, and all of the participants were able to find the potential solutions to address the problem, and these could be resolved at the concluding meeting for the paired learners

Table 4 addresses those statements that were related to aspects of flow experience. In analyzing these responses, apart from statement 6 (control), the single players and pairs had similar responses. That is, most of our subjects, irrespective of their playing mode, seemed to have a certain level of individual flow experience (above the neutral value 4 , by one sampled T-tests). The difference in the sense of control may arise from paired players not visiting all the waypoints, so they were not able to feel in full control of the information to be addressed later when giving feedback.

Table 4. Individual Flow Experience: The Four Dimensions

\begin{tabular}{|c|c|c|c|}
\hline \multicolumn{1}{|c|}{ Statement } & \multicolumn{2}{|c|}{ Mean ratings (s.d) } & Pair $(\mathrm{n}=14)$ \\
\cline { 2 - 4 } & Single $(\mathrm{n}=7)$ & $\mathrm{p}$ \\
\hline $\begin{array}{c}\text { 6. Using the game gives me a feeling of } \\
\text { control over my learning about business } \\
\text { issues (control) }\end{array}$ & $5.86(0.38)^{*}$ & $4.57(0.85)$ & $<.05$ \\
\hline $\begin{array}{c}\text { 7. Interacting with the system made me } \\
\text { curious (cognitive curiosity) }\end{array}$ & $6.00(0.58)^{*}$ & $5.29(1.20)$ & n.s \\
\hline $\begin{array}{c}\text { 8. Working with the system was interesting } \\
\text { (intrinsic interest) }\end{array}$ & $5.29(1.25)^{*}$ & $5.07(1.20)$ & n.s. \\
\hline
\end{tabular}




\begin{tabular}{|c|c|c|c|}
\hline $\begin{array}{c}\text { 9. When using the mobile device, I was } \\
\text { totally absorbed in what I was doing } \\
\text { (attention focus) }\end{array}$ & $5.86(0.69)^{*}$ & $5.21(1.43)$ & n.s. \\
\hline
\end{tabular}

* One-sampled T-test, significant at level $\mathrm{p}<.05$

The indication of individual flow experience, observed in Table 3, is not a new concept for the mobile learning community, and much literature on individual flow experience has been published. However, a particular concern of this empirical study is whether the pairplaying participants (those who did not have direct experience of one piece of critical information) would experience more boredom or frustration than single players. This was examined through three further statements, the outcomes of which are shown in Table 5. Statements 10 and 11 showed that the pairs experienced neither boredom nor frustration in the flow segmentation channel model, and they thought this game-based learning was well suited to team play (statement 12).

Table 5. Frustration and Boredom in Delayed Collaborative Learning

\begin{tabular}{|c|c|}
\hline Statement & Mean ratings (s.d) \\
\hline $\begin{array}{c}\text { 10. Working together with the game and my } \\
\text { partner bored me }\end{array}$ & $2.43(1.09)^{*}$ \\
\hline $\begin{array}{c}\text { 11. Interacting with the game and a partner is } \\
\text { frustrating. }\end{array}$ & $4.07(1.33)$ \\
\hline $\begin{array}{c}\text { 12. The game was well suited for playing as a } \\
\text { team. }\end{array}$ & $5.79(0.97)^{*}$ \\
\hline
\end{tabular}

* One-sampled T-test, significant at level $\mathrm{p}<.05$

\subsection{Extending Flow Experience: Coordinated Individual Flow}

At this point in our analysis we must engage in some speculation, which cannot at the moment be confirmed from experimental data but may be regarded as a possible interpretation that could be subject to further empirical examination. We note that an apparent advantage in applying cognitive skills by single players over team players was not reflected in negative responses about collaborative learning. We might resolve this apparent conflict by considering the effects of flow experience. Our earlier propositions about flow experience are equally applicable to co-operative learning activities. In this cooperative learning context, at any given moment, each individual must be aware of the challenges being faced, while the pair must assess together how capable they are of coping with these challenges. We might therefore question how a learning process that is team based but involves individual activity may sustain or enhance individual flow experience. Though many previous studies in the area of mobile learning have focused on either solitary or social learning activities, the study of work coordination has been lacking. However, given that many business activities are based on division of labor in separate but complementary roles, seeking further insights into work coordination and how this can be done in game-based learning would be a useful contribution to knowledge.

In the context of interpreting the results of this study we propose an analysis based on an extension of flow theory which seems appropriate to the type of scenario that we present in the game. We have termed this coordinated individual flow. This concept is based on the nature of the scenarios that we simulate in our mobile learning game. In reality, consultants may well find themselves working in teams but gathering data individually. Communication between them is unlikely to be immediate (for example a consultant would not be communicating with another consultant at the same time as conducting an interview) but subsequent coordination is essential to ensure that knowledge is shared and jointly evaluated. For the purposes of this study we previously 
termed this activity delayed collaborative learning. Thus the realistic activity of delayed collaborative learning can be assessed through the analytical lens of coordinated individual flow. Our proposed interpretation is illustrated in Figure 7. In pair-based play it is possible that both individual $\mathrm{A}$ and individual $\mathrm{B}$ might have either frustration or boredom at the individual level. This can be confirmed by statements $7-9$, where they expressed that curiosity (mean 5.29), focus of attention (mean 5.07) and interest (mean 5.21) were not significantly different from the neutral value 4 . However, when they were able to coordinate well they would have a cooperative flow experience, as shown in Figure 2 (c). This may help to explain why the paired players seemed to find some aspects of the process less clear, manageable and relevant than the single players, yet they still valued the team play. A possible implication of this is that we may find it difficult to design learning games that can equally address both cognitive and collaborative skills, rather than emphasizing one at the expense of the other. Of course, the single evaluation carried out for this study cannot generalize this contention. However, at the very least, the values in Table 4 suggest that our participants were benefitting from the exercise of collaborative skills, even if the particular game configuration appeared to have a negative impact on their expression of cognitive skills.

(a)

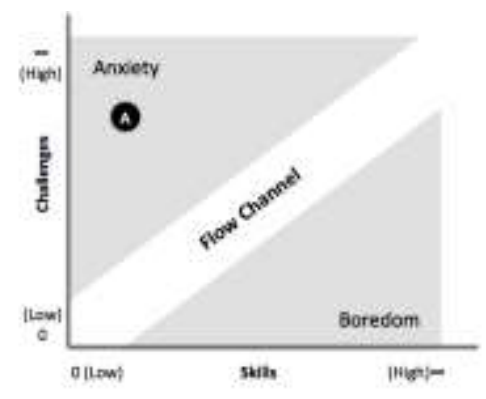

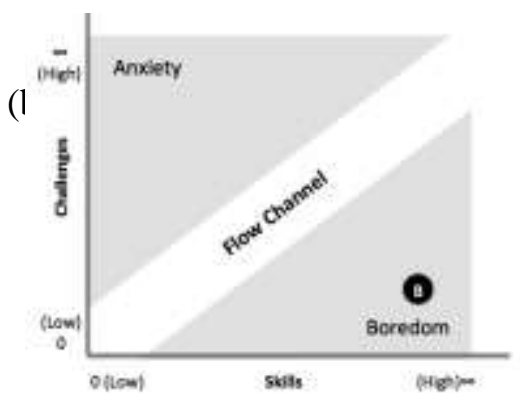

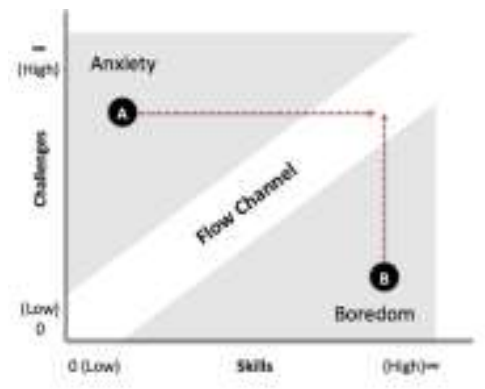

Figure 5. Dimensions of Coordinated Individual Flow Experience

\section{Conclusion}

In this paper we have outlined some important aspects of $21^{\text {st }}$ century skills, and mapped some of these to serious gaming activities, in particular those that are supported by mobile devices. We have described our own mobile serious game implementation in the context of this background and related work, characterizing it as a virtual augmented reality collaborative game. The nature of the game play has been described, along with its relationship to the development of both cognitive and collaborative skills. In seeking to analyze some aspect of our results, we have introduced the concept of delayed collaborative learning, which reflects some realistic aspects of team work where activities take place individually and are later coordinated. In seeking to explain some of our results, which seemed to indicate that single players were better able to exercise cognitive skills in the game, while team players seemed to benefit from collaboration as an experience, we have proposed an interpretation based on coordinated individual flow, which seeks to examine possible relationships between the user experience of such delayed collaborative learning and some forms of flow experience. Whilst we do not claim that this single example provides concrete evidence for our proposals, we feel that questions around possible conflicts when aiming to developing cognitive skills as well as interpersonal skills are worthy of further study. 


\section{References}

[1] M. Gibbons, "Higher Education Relevance in the 21st Century", World Bank, (1998).

[2] H-J. Chang, "23 Things They Don't Tell You About Capitalism”, London: Allen Lane, (2010).

[3] P. Altbach and P. McGill Peterson, (Eds.) "Higher Education in the 21st Century: Global Challenge and National Response". Annapolis Junction, MD: IIE Books, (1999).

[4] H. P. Vessuri, "Commission I: Relevance for Higher Education Final Report". UNESCO, (1998)

[5] Krathwohl, D. "A Revision of Bloom's Taxonomy: An Overview". Theory into Practice , (2002).

[6] Partnership for 21st Century Skills. Framework for 21st Century Learning, retrieved December 16, 2012 http://www.p21.org/storage/documents/1._p21_framework_2-pager.pdf, (2011).

[7] National Research Council. "Assessing 21st Century Skills: Summary of a Workshop. Committee on the Assessment of 21st Century Skills. Board on Testing and Assessment, Division of Behavioral and Social Sciences and Education". (J.A. Koenig, Rapporteur) Washington, DC: The National Academies Press, (2011).

[8] C. Dede, "Transforming Education for the 21st Century: New Pedagogies that Help All Students Attain Sophisticated Learning Outcomes", NCSU Friday Institute, retrieved December 16, 2012 http://thenetwork.typepad.com/files/dede_21stc-skills_semi-final.pdf, (2007).

[9] M. Prensky, "Digital Game-Based Learning". New York: McGraw-Hill, (2016).

[10] M.J. Dondlinger, "Educational video game design: A review of the literature", Journal of Applied Educational Technology, vol.4, no.1, (2007), pp. 21-31.

[11] C.T. Tan and D. Soh, "Augmented reality games: A review, In Proc. GAMEON-ARABIA, European Multidisciplinary Society for Modelling and Simulation Technology” (EUROSIS), Dec. 2010, (2010).

[12] L. Annetta, "Video Games in Education: Why They Should Be Used and How They Are Being Used". Theory Into Practice., vol. 47, no. 3, (2008), pp. 229-239.

[13] E. Bright, "Creating mobile learning and performance aids for the next generation of learners. In Proc. 8th World Conf. on Mobile and Contextual Learning", D. Metcalf, A. Hamilton, and C. Graffeo, Eds. p.128, I Am Learn, (2009).

[14] M. Kankaanranta and P. Neittaanmaki, "Design and Use of Serious Games", Berlin: Springer, (2009).

[15] V. Gilgeous and M. D'Cruz, "A study of business and management games", Management Development Review., vol. 9, no. 1, (1996), pp. 32-39.

[16] N. Bos, \& M. Gordon, "A simulated consulting project with a deregulating utility company", Simulation and Gaming., vol. 36, no. 1, (2005), pp. 91-113.

[17] C. Kittl, F. Edegger and O. Petrovic, "Learning by pervasive gaming: an empirical study", In H. Ryu \& D. Parsons, (Eds.) Innovative Mobile Learning: Techniques and Technologies, Hershey, PA: Information Science Reference, (2009).

[18] E. Klopfer, K. Squire and H. Jenkins, "Environmental Detectives: PDAs as a window into a virtual simulated world. In Proc 1st IEEE International Workshop on Wireless and Mobile Technologies in Education", (2002), pp. 92-95.

[19] K. Schrier, "Using Augmented Reality Games to Teach 21st Century Skills", ACM Press, (2006).

[20] K. Facer, et al. "Savannah: mobile gaming and learning?", Journal of Computer-Assisted Learning., vol. 20, (2004), pp. 399-409.

[21] M. Winter and L. Pemberton, "Unearthing Invisible Buildings: Device Focus and Device Sharing in a Collaborative Mobile Learning Activity", International Journal of Mobile and Blended Learning, vol. 3, no. 4, (2011), 1-18.

[22] M. Csikszentmihalyi, "Flow: The Psychology of Optimal Experience", New York: Harper Perennial, (1990).

[23] J. Nakamura and M. Csikszentmihalyi, "The construction of meaning through vital engagement. In C.L.M. Keyes and J. Haidt (Eds.), Flourishing: Positive Psychology and the Life Well-Lived", Washington, DC: American Psychological Association, (2003).

[24] J. Smith, "The road not taken - the hows and whys of interactive fiction", Game Research, retrieved December 16, 2012 from http://game-research.com/index.php/articles/the-road-not-taken-the-hows-andwhys-of-interactive-fiction, (2000).

[25] T. Webster, "Dynamic Games with Complete and Perfect Information, in Introduction to Game Theory in Business and Economics", NY: Sharpe, (2008). 


\section{Authors}
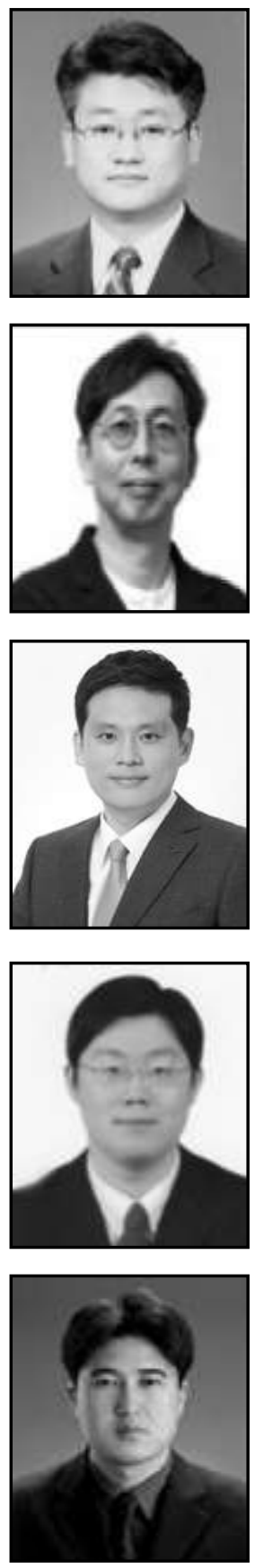

Ki-Min Song, is professor of Hanyang University. He has a lot of interest in Medical and Convergence industry. He has published many papers of these fields and given lectures for years. He received bachelor's and doctor's degrees in Hanyang University.

Ho-Kyoung Ryu, is a professor of Hanyang University. He has a lot of interest in Information Design (CID) New Product, Service Development (NPD), Learning Technology (LT), and Game-based Learning (Serious Games), HCI related problem-solving (Medical HCI/ Arts \& Technology). He has published many papers of these fields and given lectures for years. He received doctor's degrees in University of york.

Seung-Il Moon, is a professor of Hospitality Academy in Hanyang University. He has a lot of interest in IT and information. He has written many papers and books on these fields and given lectures for years. He worked as a webmaster and Internet honorary police officer.

Joo-Suk Park, is a researcher of the Department of Art Management in Seokyeong University. $\mathrm{He}$ is a former Korea National Open University lecturer. He worked in the area of IT \& administration law. He received a doctor's degree in University of Seoul.

Young-Min Song, is an associate professor of Anyang University. $\mathrm{He}$ has a lot of interest in Serious Leisure and Convergence study. He has published many papers of these fields and given lectures for years.. 